\title{
26 Resarch Square \\ Diabetes Mellitus Induced by Steroid Overtreatment in Adrenal Insufficiency: Is it Possible to Predict it?
}

\section{Valentina Guarnotta}

Azienda Ospedaliera Universitaria Policlinico "Paolo Giaccone" di Palermo

\section{Laura Tomasello}

Azienda Ospedaliera Universitaria Policlinico "Paolo Giaccone" di Palermo

Carla Giordano ( $\nabla$ carla.giordano@unipa.it)

Azienda Ospedaliera Universitaria Policlinico "Paolo Giaccone" di Palermo

\section{Research Article}

Keywords: normal glucose tolerance, prediabetes/diabetes mellitus, secondary adrenal insufficiency, anthropometric, steroid treatment

Posted Date: October 26th, 2021

DOI: https://doi.org/10.21203/rs.3.rs-965895/v1

License: (c) (i) This work is licensed under a Creative Commons Attribution 4.0 International License. Read Full License 


\section{Abstract}

Objective: To assess the differences between patients with normal glucose tolerance (NGT) and prediabetes/diabetes mellitus (DM) in secondary adrenal insufficiency (SAI).

Design and patients: We retrospectively evaluated 102, out of a total of 140 , patients with SAl, who were on hydrocortisone $(H C)(n=50)$ and cortisone acetate $(n=52)$ replacement therapy. Clinical, anthropometric, and metabolic parameters were compared in patients with NGT $(n=60)$ and DM $(n=42)$.

Results: Patients with prediabetes/DM have a more marked family history of DM ( $p=0.002), B M I$ $(p<0.001)$, higher waist circumference $(p<0.001)$, total cholesterol $(p=0.012)$, LDL-cholesterol $(p=0.004)$, triglycerides $(p=0.031)$, fasting glucose $(p=0.002)$, fasting insulin $(p=0.035)$, glutamate pyruvate transaminase $(p=0.018), \operatorname{HOMA-IR}(p=0.039)$, area under curves of glucose $(p=0.001)$ and insulin $(p=0.002), \operatorname{HbA1c}(p<0.001)$, Visceral adiposity index (VAI) $(p=0.038)$ and lower ISI-Matsuda $(p=0.008)$ and oral disposition index $(\mathrm{p}<0.001)$ than patients with NGT. Multivariate analysis showed that high doses of cortisone acetate, duration of conventional steroid replacement therapy, family history of diabetes mellitus and VAl are independent predictive factors for DM in patients with SAl.

Conclusions: High doses of cortisone acetate replacement treatment, longer duration of steroid treatment, family history of DM and VAI may be predictors of the development of DM in patients with SAI.

\section{Introduction}

Secondary adrenal insufficiency (SAI) is characterized by the failure of pituitary disease to produce ACTH. Rarely, it is isolated, while more frequently it is associated with other pituitary deficiencies such as hypothyroidism, hypogonadism and growth hormone deficiency (GHD). Subjects with SAl have higher mortality than the general population without SAI. The main causes of mortality are represented by cardiovascular disease, tumours and infections ${ }^{1}$.

Cardiovascular mortality is due to cardiovascular risk factors such as diabetes mellitus, dyslipidaemia and arterial hypertension ${ }^{2}$. Diabetes mellitus is quite frequent in patients with SAl. Excluding autoimmune diabetes mellitus, diabetes mellitus in SAl has been recognized to be due to inappropriate glucocorticoid (GC) replacement therapy ${ }^{3}$. Therapeutic steroid replacement management of SAI consists in cortisone acetate at the daily dose of 25-30 mg and hydrocortisone ( $\mathrm{HC}$ ) at the daily dose of $15-25 \mathrm{mg}$ administered in two or three doses or, as an alternative, when cortisone acetate and/or $\mathrm{HC}$ are not available, prednisolone once or twice daily at the dose of 3-5 mg/day ${ }^{4}$. As reported in many studies, patients overtreated for a long period with conventional steroids develop frequently diabetes mellitus and dyslipidaemia, while novel formulations have no impact on metabolism ${ }^{5-9}$. Discordant reports are available between the association of high doses of cortisone replacement therapy and cardiovascular mortality, higher risk of diabetes mellitus and other comorbidities ${ }^{10-12}$. Currently, the factors involved in 
the development of diabetes mellitus in patients with SAI treated with conventional steroids have not been fully investigated.

The primary aim of the current study was to assess the prevalence of glucose tolerance defects in a population of patients with SAI and to evaluate the differences between patients with normal glucose tolerance (NGT) and patients with prediabetes and diabetes mellitus. The secondary aim was to identify predictive factors for the development of diabetes mellitus in order better to personalize steroid replacement treatment.

\section{Materials And Methods Study participants}

We evaluated data from 102 consecutive patients with SAI due to hypopituitarism, out of a total of 140 patients who were on conventional GC treatment. The patients were consecutively referred to the Division of Endocrinology of Palermo University from January 2010 to December 2020. All patients had a disease duration of at least five years. Inclusion criteria were the following: age 18-75 years, diagnosis of SAl, ongoing daily conventional GC treatment for at least 5 years, stable replacement dose with levo-thyroxine, testosterone, estrogen and $\mathrm{GH}$ for at least 3 months before inclusion and during follow-up, stable dose of cortisone acetate and $\mathrm{HC}$ for at least 6 months or more, before inclusion in the study. Exclusion criteria were pregnancy, lactation, primary adrenal insufficiency and treatment with dual-release hydrocortisone.

Fifty patients were on $\mathrm{HC}$ replacement treatment, while 52 were on cortisone acetate therapy.

SAl was diagnosed as recommended by international guidelines ${ }^{13}$. The metabolic syndrome was diagnosed according to the NCEP ATP III criteria, whereas diabetes mellitus and prediabetes were diagnosed according to the ADA criteria ${ }^{14,15}$. We defined visceral obesity as the presence of waist circumference over $102 \mathrm{~cm}$ in males or $88 \mathrm{~cm}$ in females.

Overall, 60 patients had normal glucose tolerance, while 42 had prediabetes/diabetes mellitus.

The characteristics of the patients with SAI and the other endocrine deficiency combinations are shown in Table 1. Patients with hypothyroidism were treated with levo-thyroxine at the average dose of $1 \mathrm{mcg} / \mathrm{kg}$. Patients with GHD were treated with somatotropin at the average dose of $0.4 \mathrm{mg} /$ day. Males with hypogonadism were treated with an average injected monthly dose of testosterone enanthate $250 \mathrm{mg}$. Premenopausal females were treated with a low dose of estrogen and progesterone therapy. No history of chronic GC use before substitutive treatment was known for patients with SAI. 
Table 1

Clinical and biochemical features of all patients with adrenal insufficiency divided into normal glucose tolerance and diabetes mellitus at onset

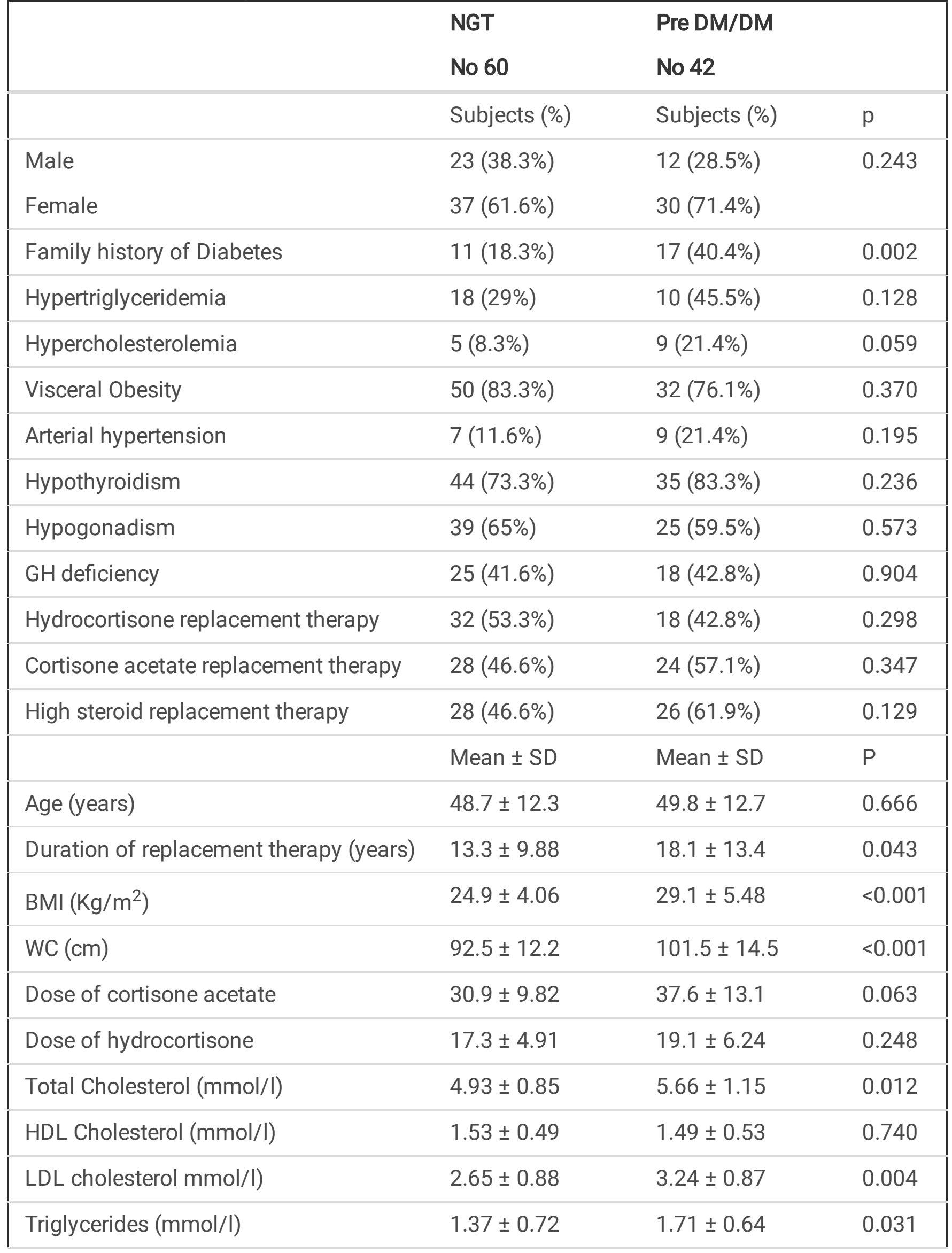




\begin{tabular}{|llll|}
\hline & NGT & Pre DM/DM & \\
& No 60 & No 42 & \\
\hline Fasting glucose (mmol/l) & $4.46 \pm 0.51$ & $7.13 \pm 4.65$ & 0.002 \\
\hline Fasting insulin (UI/ml) & $7.54 \pm 4.41$ & $12.7 \pm 9.23$ & 0.035 \\
\hline GOT (U/L) & $19.9 \pm 9.07$ & $24.2 \pm 12.2$ & 0.178 \\
\hline GPT (U/L) & $17.5 \pm 8.95$ & $27.5 \pm 19.2$ & 0.018 \\
\hline Homa 2-IR & $1.46 \pm 0.92$ & $2.47 \pm 1.76$ & 0.039 \\
\hline AUC ${ }_{2 h}$ glucose & $12804.1 \pm 2717.5$ & $17758.2 \pm 4666.9$ & 0.001 \\
\hline AUC ${ }_{2 h}$ insulin & $6828.5 \pm 5382.1$ & $14294.3 \pm 7824.4$ & 0.002 \\
\hline ISI Matsuda & $10.8 \pm 9.55$ & $2.57 \pm 1.25$ & 0.008 \\
\hline Oral Disposition Index (Dlo)* & $6.39 \pm 2.47$ & $1.95 \pm 1.47$ & $<0.001$ \\
\hline HbA1c (\%) & $5.33 \pm 0.43$ & $6.99 \pm 1.96$ & $<0.001$ \\
\hline VAl & $1.76 \pm 1.36$ & $2.54 \pm 1.28$ & 0.038 \\
\hline
\end{tabular}

This study was carried out in accordance with the recommendations of the Paolo Giaccone Policlinico ethics committee with written informed consent from all subjects, in accordance with the Declaration of Helsinki. The protocol was approved by the Paolo Giaccone Policlinico ethics committee.

\section{Study design}

In this retrospective, real-life study we investigated the effects of cortisone replacement therapy in patients with SAI. Patients were subdivided into two groups: NGT (normal glucose tolerance) and prediabetes/diabetes mellitus. Body mass index (BMI), waist circumference (WC) measured at the midpoint between the lower rib and the iliac crest, and waist/hip ratio (WHR) were evaluated. Lipid profile [total, high-density lipoprotein (HDL) and low-density lipoprotein cholesterol (LDL), triglycerides], haemoglobin $\mathrm{A} 1 \mathrm{c}(\mathrm{HbA} 1 \mathrm{c})$, glycaemia and serum insulin were extracted after overnight fasting.

Oral glucose tolerance test was carried out by measuring plasma blood glucose and insulin levels every 30 min for 2 hours after a $75-\mathrm{g}$ of oral glucose load.

Insulin sensitivity was estimated indirectly using basal insulin and glucose values to calculate the homeostatic model of insulin resistance (HOMA2-IR) [glycemia $(\mathrm{mmol} / \mathrm{l}) \mathrm{X}$ insulinemia $(\mu \mathrm{U} / \mathrm{ml}) / 22,5]$ and using glucose and insulin values during OGTT to calculate the Matsuda index of insulin sensitivity (ISI Matsuda) $(10000 / \text { glucose }(\mathrm{mg} / \mathrm{dl}) \mathrm{X} \text { insulin }(\mu \mathrm{U} / \mathrm{ml}) \mathrm{X} \text { glucose mean } \mathrm{X} \text { insulin mean })^{16,17}$. A composite measure of $\beta$-cell function relative to insulin sensitivity, assessed by Oral Disposition Index (Dlo), was 
calculated as ( $\Delta$ Insulin $_{0_{-30}} / \Delta$ Glucose $\left._{0_{-}} 30\right) X(1 /$ fasting insulin). The trapezoidal method was used for calculation of the areas under the curves for insulin $\left(\mathrm{AUC}_{2 \mathrm{hlnsulin}}\right)$ and glucose $\left(\mathrm{AUC}_{2 \mathrm{hglucose}}\right)^{18}$.

The Visceral Adiposity Index (VAl) was calculated according to gender, where TG is triglycerides expressed in $\mathrm{mmol} / \mathrm{l}$ and $\mathrm{HDL}$ is HDL-cholesterol levels expressed in $\mathrm{mmol} / \mathrm{l}$ :

- Males VAI $=[\mathrm{WC} / 39.68+(1.88 \times \mathrm{BMI})] \times(\mathrm{TG} / 1.03) \times(1.31 / \mathrm{HDL})$;

- Females, $\mathrm{VAl}=[\mathrm{WC} / 36.58+(1.89 \times \mathrm{BMI})] \times(\mathrm{TG} / 0.81) \times(1.52 / \mathrm{HDL})^{19}$.

\section{Hormone and biochemical assays}

Serum insulin, glycaemia and lipid levels were measured by ELISA (DRG instruments GmbH, Germany) as previously reported ${ }^{7}$. The normal insulin range was 5-19 UI/ml. LDL cholesterol was measured using the Friedewald formula [total cholesterol $-(\mathrm{HDL}+(\mathrm{TG} / 5)]$. HbA1c was determined by High Pressure Liquid Chromatography (HPLC) with ion-exchange resin (HA8121, Hi-AutoA1c, Menarini Italy). The conversion factors for the International System (SI) were the following: glucose $\mathrm{mg} / \mathrm{dl} \mathrm{vs.} \mathrm{mmol} / \mathrm{l}: 0.0555$, insulin $\mathrm{mUl} / \mathrm{ml}$ vs. pmol/l: 6.945 , total and $\mathrm{HDL}$ cholesterol $\mathrm{mg} / \mathrm{dl}$ vs. $\mathrm{mmol} / \mathrm{l}: 0.0259$, triglycerides $\mathrm{mg} / \mathrm{dl}$ vs. $\mathrm{mmol} / \mathrm{l}: 0.0113$.

\section{Statistical analysis}

SPSS version 17 was used for data analysis as previously reported ${ }^{7}$. Baseline characteristics were presented as mean \pm SD for continuous variables; rates and proportions were calculated for categorical data. Normality of distribution for quantitative data was assessed by the Shapiro-Wilk test. The differences between patients with NGT and prediabetes/DM were detected by Student's t test for continuous variables and by the chi-square test for categorical variables. Crude odds ratios (OR) and their $95 \%$ confidence interval $(\mathrm{Cl})$ for the association of diabetes with potential risk factors in SAI were calculated by univariate analysis. Adjusted ORs were calculated by stepwise logistic regression analysis to identify factors independently associated with development of diabetes. Only factors significantly associated with diabetes mellitus by univariate analysis were included in the logistic regression analysis. A receiver operating characteristic $(\mathrm{ROC})$ analysis was performed to investigate the diagnostic ability of significantly associated risk factors to predict diabetes. The ROC curve is plotted as sensitivity versus 1specificity. The area under the ROC curve (AUC) was estimated to measure the overall performance of the predictive factors for diabetes mellitus. A $p$ value of $<0.05$ was considered statistically significant.

\section{Results}

Of 102 patients with SAl, 42 were classified as having a defect in glucose metabolism, such as prediabetes or diabetes mellitus. Higher frequency of family history of diabetes $(p=0.002)$ was found in patients with prediabetes/DM than NGT (Table 1). Patients with prediabetes/DM had higher BMI $(p<0.001)$, WC $(p<0.001)$, total cholesterol $(p=0.012)$, LDL-cholesterol $(p=0.004), T G(p=0.031)$, fasting glucose $(p=0.002)$, fasting insulin $(p=0.035)$, glutamate-pyruvate transaminase (GPT) $(p=0.018)$, HOMA- 
IR ( $p=0.039), A_{2 h}$ glucose $(p=0.001), A U C_{2 h \text { insulin }}(p=0.002), \operatorname{HbA1c}(p<0.001), \operatorname{VAl}(p=0.038)$ and lower ISI-Matsuda $(p=0.008)$ and Dlo $(p<0.001)$ than patients with NGT (Table 1$)$.

After, we compared patients with $\mathrm{DM}$ on $\mathrm{HC}$ and cortisone acetate therapy and observed that patients treated with HC had lower TG $(p=0.007)$ and VAI $(p=0.010)$ and higher HDL-cholesterol $(p=0.005)$ than those treated with cortisone acetate (Table 2). 
Table 2

Hydrocortisone vs. cortisone acetate replacement therapy in patients with diabetes/prediabetes

\begin{tabular}{|c|c|c|c|}
\hline \multicolumn{4}{|l|}{ DM/Prediabetes } \\
\hline \multicolumn{4}{|l|}{ No 42} \\
\hline & Hydrocortisone & Cortisone acetate & \\
\hline & No 18 & No 24 & \\
\hline & Mean \pm SD & Mean \pm SD & $\mathrm{P}$ \\
\hline Age (years) & $46.5 \pm 13.5$ & $53.5 \pm 10.3$ & 0.087 \\
\hline Duration of disease (years) & $17.4 \pm 14.9$ & $18.8 \pm 12.2$ & 0.757 \\
\hline $\mathrm{BMI}\left(\mathrm{Kg} / \mathrm{m}^{2}\right)$ & $27.4 \pm 5.11$ & $30.1 \pm 5.54$ & 0.141 \\
\hline \multirow[t]{2}{*}{ WC (cm) } & $97.4 \pm 11.6$ & $103.5 \pm 15.8$ & 0.203 \\
\hline & Subjects (\%) & Subjects (\%) & \\
\hline Male & $7(38.8 \%)$ & $6(25 \%)$ & 0.344 \\
\hline Female & $11(61.1 \%)$ & $18(75 \%)$ & \\
\hline Family history of Diabetes & $5(27.7 \%)$ & $12(50 \%)$ & 0.149 \\
\hline Arterial hypertension & $5(27.7 \%)$ & $8(33.3 \%)$ & 0.701 \\
\hline Hypertriglyceridemia & $10(55.5 \%)$ & $18(75 \%)$ & 0.190 \\
\hline Hypercholesterolemia & $3(16.6 \%)$ & $6(25 \%)$ & 0.516 \\
\hline \multirow[t]{2}{*}{ Visceral obesity } & $16(88.8 \%)$ & $16(66.6 \%)$ & 0.099 \\
\hline & Mean \pm SD & Mean \pm SD & $P$ \\
\hline \multicolumn{4}{|l|}{ Metabolic parameters } \\
\hline Total Cholesterol $(\mathrm{mmol} / \mathrm{l})$ & $5.65 \pm 1.41$ & $5.64 \pm 0.96$ & 0.979 \\
\hline HDL Cholesterol (mmol/l) & $1.78 \pm 0.57$ & $1.26 \pm 0.31$ & 0.005 \\
\hline LDL cholesterol mmol/l) & $3.06 \pm 0.97$ & $3.39 \pm 0.87$ & 0.338 \\
\hline Triglycerides (mmol/l) & $1.43 \pm 0.53$ & $1.99 \pm 0.51$ & 0.007 \\
\hline Fasting glucose (mmol/l) & $5.61 \pm 2.51$ & $8.41 \pm 5.63$ & 0.085 \\
\hline Fasting insulin (Ul/ml) & $10.7 \pm 9.39$ & $14.2 \pm 9.05$ & 0.514 \\
\hline GOT (U/L) & $21.3 \pm 16.9$ & $25.9 \pm 6.57$ & 0.398 \\
\hline GPT (U/L) & $25.6 \pm 17.05$ & $28.4 \pm 9.99$ & 0.687 \\
\hline
\end{tabular}




\begin{tabular}{|llll|}
\hline $\begin{array}{l}\text { DM/Prediabetes } \\
\text { No } 42\end{array}$ & & & \\
\hline Homa 2-IR & $2.19 \pm 1.56$ & $2.99 \pm 2.15$ & 0.384 \\
\hline HbA1c (\%) & $6.87 \pm 1.10$ & $7.78 \pm 1.76$ & 0.070 \\
\hline VAl & $1.85 \pm 0.94$ & $3.18 \pm 1.25$ & 0.010 \\
\hline
\end{tabular}

The comparison between patients on high and low doses of steroids showed that patients on treatment with high doses had higher BMI ( $p=0.003)$, WC $(p=0.034)$, fasting glucose $(p=0.008)$ and higher frequency of visceral obesity $(p=0.018)$, than those treated with low doses (Table 3$)$. 
Table 3

High vs. low doses of steroid replacement therapy in patients with diabetes/prediabetes

\begin{tabular}{|c|c|c|c|}
\hline \multicolumn{4}{|l|}{$\begin{array}{l}\text { DM/Prediabetes } \\
\text { No } 42\end{array}$} \\
\hline & Low doses & High doses & \\
\hline & No 16 & No 26 & \\
\hline & Mean \pm SD & Mean \pm SD & $P$ \\
\hline Age (years) & $45 \pm 10.9$ & $52.2 \pm 12.4$ & 0.102 \\
\hline Duration of disease (years) & $16.8 \pm 14.1$ & $18.7 \pm 12.1$ & 0.699 \\
\hline $\mathrm{BMI}\left(\mathrm{Kg} / \mathrm{m}^{2}\right)$ & $24.9 \pm 4.77$ & $30.4 \pm 4.91$ & 0.003 \\
\hline \multirow[t]{2}{*}{ WC $(\mathrm{cm})$} & $93.1 \pm 13.1$ & $103.9 \pm 13.4$ & 0.034 \\
\hline & Subjects (\%) & Subjects (\%) & \\
\hline Male & $7(43.7 \%)$ & $6(23.1 \%)$ & 0.165 \\
\hline Female & $9(56.3 \%)$ & $20(76.9 \%)$ & \\
\hline Family history of Diabetes & $5(31.2 \%)$ & $12(46.1 \%)$ & 0.345 \\
\hline Arterial hypertension & $3(18.7 \%)$ & $10(38.4 \%)$ & 0.184 \\
\hline Hypertriglyceridemia & $5(31.2 \%)$ & $13(50 \%)$ & 0.237 \\
\hline Hypercholesterolemia & $2(12.5 \%)$ & $7(26.9 \%)$ & 0.275 \\
\hline Visceral obesity & $9(56.2 \%)$ & $23(88.4 \%)$ & 0.018 \\
\hline Hydrocortisone replacement therapy & $9(56.2 \%)$ & $9(34.6 \%)$ & 0.174 \\
\hline \multirow[t]{2}{*}{ Cortisone acetate replacement therapy } & $8(50 \%)$ & $16(61.5 \%)$ & 0.470 \\
\hline & Mean \pm SD & Mean \pm SD & $P$ \\
\hline \multicolumn{4}{|l|}{ Metabolic parameters } \\
\hline Total Cholesterol (mmol/l) & $5.87 \pm 1.25$ & $5.48 \pm 1.01$ & 0.300 \\
\hline HDL Cholesterol (mmol/l) & $1.59 \pm 0.56$ & $1.51 \pm 0.53$ & 0.734 \\
\hline LDL cholesterol mmol/l) & $3.36 \pm 0.92$ & $3.14 \pm 0.95$ & 0.557 \\
\hline Triglycerides (mmol/l) & $1.61 \pm 0.47$ & $1.73 \pm 0.65$ & 0.617 \\
\hline Fasting glucose (mmol/l) & $4.86 \pm 0.65$ & $7.98 \pm 5.21$ & 0.008 \\
\hline Fasting insulin (Ul/ml) & $9.41 \pm 7.99$ & $13.9 \pm 10.7$ & 0.365 \\
\hline
\end{tabular}




\begin{tabular}{|llll|}
\hline DM/Prediabetes \\
No 42
\end{tabular}

A multiple logistic regression model was fitted by using the abovementioned risk factors as potential predictors for diabetes mellitus (Table 4$)$. Our model demonstrates that BMI $(p=0.012)$, dose of cortisone acetate $(p=0.014)$, duration of disease $(p=0.009)$, VAl $(p=0.003), T G(p=0.011)$ and family history of diabetes $(p=0.004)$ were statistically significant factors for predicting the development of diabetes mellitus in SAI (Table 4). A ROC curve was constructed, and a prediction model was established with a moderately robust power $(\mathrm{AUC}=0.73)$ to predict diabetes mellitus in patients with SAl. At multivariate analysis, dose of cortisone acetate, duration of steroid treatment, family history of diabetes mellitus and VAl were found to be predictors of diabetes mellitus (Figure 1). A p value $<0.005$ was statistically significant. 
Table 4

Risk factors associated with diabetes mellitus in patients with SAI

\begin{tabular}{|c|c|c|c|}
\hline Variable & $\begin{array}{l}\text { DM/preDM } \\
\left(N^{\circ}=42\right)\end{array}$ & $\begin{array}{l}\text { NO-DM } \\
\left(N^{\circ}=60\right)\end{array}$ & Crude OR (95\% Cl) \\
\hline \multicolumn{4}{|l|}{ BMI } \\
\hline$\leq 22.8 \mathrm{Kg} / \mathrm{m}^{2}$ & $3(7.7 \%)$ & $22(36.6 \%)$ & 1 \\
\hline$>22.8 \mathrm{Kg} / \mathrm{m}^{2}$ & $39(92.3 \%)$ & $38(63.4 \%)$ & $6.93(1.51-31.7)$ \\
\hline \multicolumn{4}{|c|}{ Waist circumference } \\
\hline$\leq 91 \mathrm{~cm}$ & $10(23.1 \%)$ & $33(54.9 \%)$ & 1 \\
\hline$>91 \mathrm{~cm}$ & $32(76.9 \%)$ & $27(46.1 \%)$ & $2.73(0.98-7.62)$ \\
\hline \multicolumn{4}{|c|}{ Dose of cortisone acetate } \\
\hline$\leq 25 \mathrm{mg} /$ day & $5(12.5 \%)$ & $29(47.8 \%)$ & 1 \\
\hline$>25 \mathrm{mg} /$ day & $37(87.5 \%)$ & $31(52.2 \%)$ & $6.41(1.31-31.4)$ \\
\hline \multicolumn{4}{|c|}{ Duration of disease } \\
\hline$<16$ years & $16(38.5 \%)$ & $42(69.3 \%)$ & 1 \\
\hline$\geq 16$ years & $26(61.5 \%)$ & $18(30.7 \%)$ & $3.61(1.42-9.16)$ \\
\hline \multicolumn{4}{|l|}{ VAl } \\
\hline$\leq 1.74$ & $11(4 \%)$ & $38(63.9 \%)$ & 1 \\
\hline$>1.74$ & $31(75 \%)$ & $22(36.1 \%)$ & $5.31(1.41-19.8)$ \\
\hline \multicolumn{4}{|l|}{ Total cholesterol } \\
\hline$\leq 6.01 \mathrm{mmol} / \mathrm{L}$ & $28(66.7 \%)$ & $52(87.3 \%)$ & 1 \\
\hline$>6.01 \mathrm{mmol} / \mathrm{L}$ & $14(33.3 \%)$ & $8(12.7 \%)$ & $3.43(1.06-11.1)$ \\
\hline \multicolumn{4}{|l|}{ LDL-cholesterol } \\
\hline$\leq 2.36 \mathrm{mmol} / \mathrm{L}$ & $6(14.3 \%)$ & $17(28.8 \%)$ & 1 \\
\hline$>2.36 \mathrm{mmol} / \mathrm{L}$ & $36(85.7 \%)$ & $43(71.2 \%)$ & $2.42(0.63-9.32)$ \\
\hline \multicolumn{4}{|l|}{ Triglycerides } \\
\hline$\leq 1.62 \mathrm{mmol} / \mathrm{L}$ & $18(42.9 \%)$ & $42(69.8 \%)$ & 1 \\
\hline$>1.62 \mathrm{mmol} / \mathrm{L}$ & $24(57.1 \%)$ & $18(30.2 \%)$ & $3.08(1.11-8.64)$ \\
\hline
\end{tabular}




\begin{tabular}{|llll|}
\hline Variable & $\begin{array}{l}\text { DM/preDM } \\
\left(\mathbf{N}^{\circ}=42\right)\end{array}$ & $\begin{array}{l}\text { NO-DM } \\
\left(\mathbf{N}^{\circ}=60\right)\end{array}$ & Crude OR (95\% Cl) \\
\hline GPT & & & \\
$\leq 28 \mathrm{U} / \mathrm{L}$ & $26(62.5 \%)$ & $53(88.6 \%)$ & 1 \\
$>28 \mathrm{U} / \mathrm{L}$ & $16(37.5 \%)$ & $7(11.4 \%)$ & $4.65(1.08-19.8)$ \\
\hline Familial history of diabetes & & & \\
No & $19(46.6 \%)$ & $49(81.3 \%)$ & 1 \\
Yes & $23(53.8 \%)$ & $11(18.7 \%)$ & $2.5(0.9-6.94)$ \\
\hline
\end{tabular}

\section{Declarations}

Competing interest: The authors declare no competing interests.

Funding: This research did not receive any specific grant from any funding agency in the public, commercial or non-profit sector

Acknowledgments: Thanks to Prof. D. Gailor for revising the language of the manuscript.

Author contributions: VG, LT and CG had full control of study design, data analysis and interpretation, and preparation of the article. All authors were involved in planning the analysis and drafting the article. The final draft article was approved by all the authors.

\section{References}

1. Ngaosuwan, K., Johnston, D.G., Godsland, I.F., Cox, J., Majeed, A., Quint, J.K. et al. Increased mortality risk in patients with primary and secondary adrenal insufficiency. $J$ Clin Endocrinol Metab. 106, e2759-e2768 (2021).

2. Stewart, P.M., Biller, B.M., Marelli, C., Gunnarsson, C., Ryan, M.P. \& Johannsson G. Exploring inpatient hospitalizations and morbidity in patients with adrenal insufficiency. $J$ Clin Endocrinol Metab. 101, 4843-4850 (2016).

3. Mazziotti, G., Formenti, A.M., Frara, S., Roca, E., Mortini, P., Berruti, A. et al. Management of endocrine disease: risk of overtreatment in patients withadrenal insufficiency: current and emerging aspects. Eur J Endocrinol. 177, R231-48 (2017).

4. Bornstein, S.R., Allolio, B., Arlt, W., Barthel, A., Don-Wauchope, A., Hammer, G.D. et al. Diagnosis and Treatment of Primary Adrenal Insufficiency: An Endocrine Society Clinical Practice Guideline. J Clin 
Endocrinol Metab. 101, 364-89 (2016).

5. Graziadio, C., Hasenmajer, V., Venneri, M.A., Gianfrilli, D., Isidori, A.M. \& Sbardella, E. Glycometabolic Alterations in Secondary Adrenal Insufficiency: Does Replacement Therapy Play a Role? Front Endocrinol (Lausanne). 9, 434 (2018).

6. Giordano, R., Marzotti, S., Balbo, M., Romagnoli, S., Marinazzo, E., Berardelli, R. et al. Metabolic and cardiovascular profile in patients with Addison's disease under conventional glucocorticoid replacement. J Endocrinol Invest. 32:917-923 (2009).

7. Guarnotta, V., Ciresi, A., Pillitteri, G. \& Giordano, C. Improved insulin sensitivity and secretion in prediabetic patients with adrenal insufficiency on dual-release hydrocortisone treatment: a 36-month retrospective analysis. Clin Endocrinol. 88, 665-672 (2018).

8. Filipsson, H., Monson, J.P., Koltowska-Haggstrom, M., Mattsson, A. \& Johannsson, G. The impact of glucocorticoid replacement regimens on metabolic outcome and comorbidity in hypopituitary patients. J Clin Endocrinol Metab. 91, 3954-3961 (2006).

9. Guarnotta, V., Amodei, R. \& Giordano, C. Metabolic comorbidities of adrenal insufficiency: Focus on steroid replacement therapy and chronopharmacology. Curr Opin Pharmacol. 60, 123-132 (2021).

10. Dunne, F.P., Elliot, P., Gammage, M.D., Stallard, T., Ryan, T., Sheppard, M.C. et al. Cardiovascular function and glucocorticoid replacement in patients with hypopituitarism. Clin Endocrinol (Oxf). 43, 623-629 (1995).

11. Danilowicz, K., Bruno, O.D., Manavela, M., Gomez, R.M. \&Barkan, A. Correction of cortisol overreplacement ameliorates morbidities in patients with hypopituitarism: a pilot study. Pituitary. 11, 279-285 (2008).

12. Petersons, C.J., Mangelsdorf, B.L., Thompson, C.H. \& Burt, M.G. Acute effect of increasing glucocorticoid replacement dose on cardiovascular risk and insulin sensitivity in patients with adrenocorticotrophin deficiency. J Clin Endocrinol Metab. 99, 2269-2276 (2014).

13. Bornstein, S.R., Allolio, B., Arlt, W., Barthel, A., Don-Wauchope, A., Hammer, G.D. et al. Diagnosis and Treatment of Primary Adrenal Insufficiency: An Endocrine Society Clinical Practice Guideline. J Clin Endocrinol Metab. 101, 364-389 (2016).

14. Expert Panel on Detection, Evaluation, and Treatment of High Blood Cholesterol in Adults. Executive summary of the third report of the National Cholesterol Education Program (NCEP) expert panel on detection, evaluation, and treatment of high blood cholesterol in adults (adult treatment panel III). JAMA 285, 2486-2497 (2001).

15. American Diabetes Association. Classification and Diagnosis of Diabetes: Standards of Medical Care in Diabetes-2020. Diabetes Care. 43, S14-S31 (2020).

16. Matthews, D., Hosker, J., Rudenski, A., Naylor, B.A., Treacher, D.F.\& Turner, R.C. Homeostasis model assessment: Insulin resistance and beta-cell function from fasting plasma glucose and insulin concentration in man. Diabetologia 28, $412-419$ (1985).

17. Matsuda, M.\& DeFronzo, R. Insulin sensitivity indices obtained from oral glucose tolerance testing: comparison with the euglycemic insulin clamp. Diabetes Care 22, 1462-1470 (1999). 
18. Utzschneider, K.M., Prigeon, R.L., Faulenbach, M.V., Tong, J., Carr, D.B., Boyko, E.J., et al. Oral disposition index predicts the development of future diabetes above and beyond fasting and $2-\mathrm{h}$ glucose levels. Diabetes Care. 32, 335-41 (2009).

19. Amato, M.C., Giordano, C., Galia, M., Criscimanna, A., Vitabile, S., Midiri M et al. AlkaMesy Study Group (2010) Visceral Adiposity Index: a reliable indicator of visceral fat function associated with cardiometabolic risk. Diabetes care. 33, 920-922 (2010).

20. Kuo, T, McQueen, A., Chen, T.C. \&Wang, J.C. Regulation of Glucose Homeostasis by Glucocorticoids. Adv Exp Med Biol. 872, 99-126 (2015).

21. Malerbi, D., Liberman, B., Giurno-Filho, A, Giannella-Neto, D. \& Wajchenberg, B.L. Glucocorticoids and glucose metabolism: hepatic glucose production in untreated Addisonian patients and on two different levels of glucocorticoid administration. Clin Endocrinol (Oxf). 28, 415-422 (1988).

22. Rafacho, A., Ortsater, H., Nadal, A. \& Quesada, I. Glucocorticoid treatment and endocrine pancreas function: implications for glucose homeostasis, insulin resistance and diabetes. Eur J Endocrinol. 223, R49-R62 (2014).

23. Geer, E.B., Islam, J. \& Buettner, C. Mechanisms of glucocorticoid-induced insulin resistance: Focus on adipose tissue function and lipid metabolism. Endocrinol Metab Clin North Am. 43, 75-102 (2014).

24. Rebuffe-Scrive, M., Krotkiewski, M., Elfverson, J. \& Björntorp, P. Muscle and adipose tissue morphology and metabolism in Cushing's syndrome. J Clin Endocrinol Metab. 67, 1122-1128 (1988).

25. Quinkler, M., Ekman, B., Marelli, C., Uddin, S., Zelissen, P., Murray, R.D., et al. Prednisolone is associated with a worse lipid profile than hydrocortisone in patients with adrenal insufficiency. Endocr Connect. 6, 1-8 (2017)

26. Smith, D.J.F., Prabhudev, H., Choudhury, S. \& Meeran, K Prednisolone has the same cardiovascular risk profile as hydrocortisone in glucocorticoid replacement. Endocr Connect. 6, 766-72 (2017).

27. Ekstrand, E., Esposito, D., Ragnarsson, O., Isgaard, J. \& Johannsson, G. Metabolic Effects of Cortisone Acetate vs Hydrocortisone in Patients With Secondary Adrenal Insufficiency. J Endocr Soc.

4, bvaa160 (2020).

28. Guarnotta, V., Di Stefano, C., Santoro, A., Ciresi, A., Coppola, A. \&Giordano, C. Dual-release hydrocortisone vs conventional glucocorticoids in adrenal insufficiency. Endocr Connect. 8:853-862 (2019).

29. Skov, J., Sundström, A., Ludvigsson, J.F., Kämpe, O. \& Bensing, S. Sex-Specific Risk of Cardiovascular Disease in Autoimmune Addison Disease-A Population-Based Cohort Study. J Clin Endocrinol Metab. 104, 2031-2040 (2019)

30. Castinetti, F., Sahnoun, M., Albarel, F., Morange, I., Philippon, M., Conte-Devolx B et al. An observational study on adrenal insufficiency in a French tertiary centre: Real life versus theory. Ann Endocrinol (Paris). 76, 1-8 (2015).

31. Behan, L.A., Carmody, D., Rogers, B., Hannon, M.J., Davenport, C., Tormey, W., et al. Low-dose hydrocortisone replacement is associated with improved arterial stiffness index and blood pressure 
dynamics in severely adrenocorticotrophin-deficient hypopituitary male patients. Eur J Endocrinol. 174, 791-799 (2016).

32. Ashcroft, F.M. \& Rorsman, P. Diabetes mellitus and the $\beta$ cell: the last ten years. Cell. 148, 1160-71 (2012).

33. Alkhalaqi, A., Al-Naimi, F., Qassmi, R., Shi, Z., Ganji, V., Salih, R., et al. Visceral adiposity index is a better predictor of type 2 diabetes than body mass index in Qatari population. Medicine (Baltimore). 99, e21327 (2020).

\section{Figures}

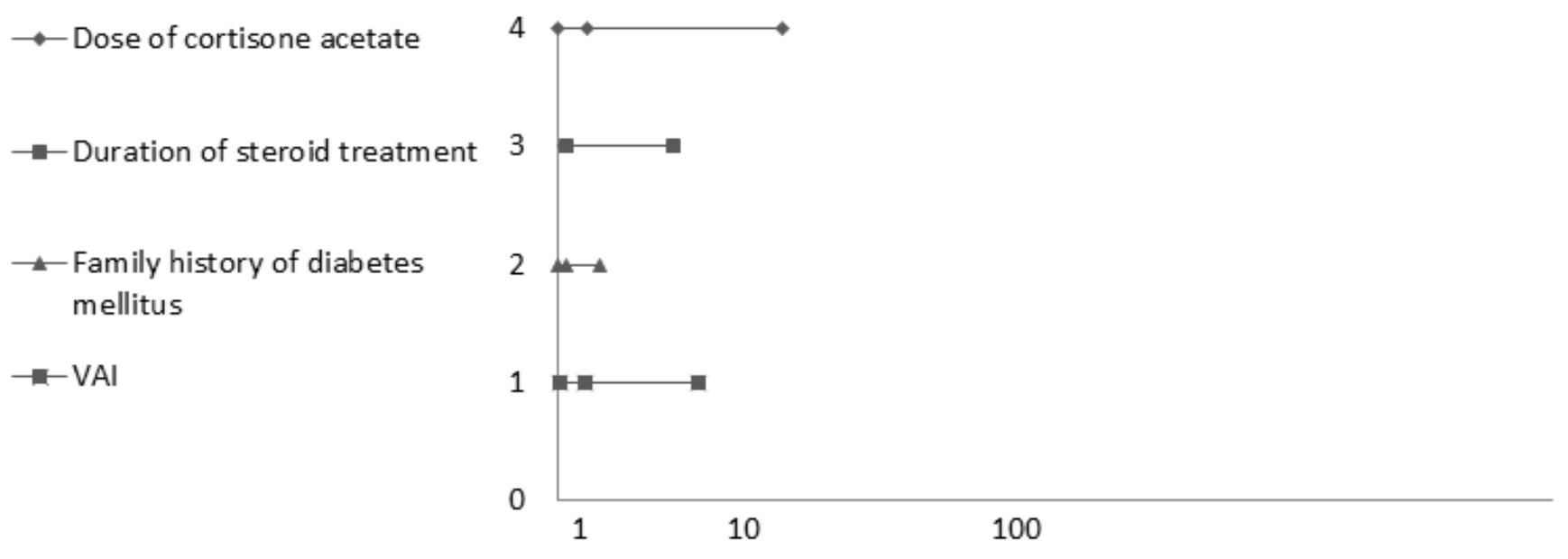

\section{Figure 1}

A Forest Plot showing odds ratio values and 95\% confidence intervals for: DM and SAI, adjusted by BMI and triglycerides. The $x$-axis represents the odds ratio (circles, square, rhombus and triangles) and $95 \%$ confidence intervals (whiskers). The dashed vertical line indicates an OR value of 1 . 